\title{
CULTURAL STUDIES AS RHIZOME - RHIZOMES IN CULTURAL STUDIES
}

\author{
SIMON O'SULLIVAN
}

\begin{abstract}
This essay reconfigures the question of cultural studies and interdisciplinarity using Deleuze's and Guattari's concepts. Proposed is a different geometry of cultural studies - a geometry in which movement takes precedence over stasis and definition. In order to theorise cultural studies as a plane of consistency in contact and connection with other plateaus and 'peopled' by intense thresholds and haecceities - it is important not only to take into account cultural studies' relation to existing strata (Cultural studies as a line of flight) but also, and at the same time, its continuing stratification (institutionalisations) and future lines of flight (deterritorialisations away from and beyond cultural studies). Formulating the questions of interdisciplinarity and institutionalization in these terms allows for a more dynamic mapping of the relation between centers and margins (strata and movement) and opens up new ways of looking at ethical issues of deterritorialisation and subjectivity. In conclusion, a notion of cultural studies as experimentation is proposed - away from cultural studies as the 'interpretation of culture' and towards a pragmatics which allows for a mapping of connections between different objects and practices, events and assemblages.
\end{abstract}

It seems to me that there are a series of assumptions behind cultural studies assumptions which themselves produce the problem - or anxiety - of interdisciplinarity. Perhaps the most pertinent assumption is that cultural studies has a position within the academy, that is to say, is itself a discipline, at least of sorts. No doubt cultural studies departments - and centres - have to fight their corner. There is a certain pragmatics at work here: departments need funding, etc. But there is also a project of demarcation at work. In defining their area of enquiry - albeit, if Derrida is on the syllabus, by delimiting what they are not cultural studies departments achieve a vicarious victory against the anxiety of homelessness. Those working within cultural studies have to earn their bread: hence the proliferation of journals, conferences, readers, etc., aimed specifically, at least in one sense, at demarcating a space, a project, for cultural studies. And this anxiety is tied into questions of pedagogy: cultural studies has to be something that can be taught. As such it must have at least a semi- coherent area of inquiry or else it risks take over moves, merger threats from other disciplines, other departments. Hence the anxiety about interdisciplinarity. 
But, I think, there is a more powerful assumption behind cultural studies, an assumption that can perhaps be summed up with one word: interpretation. For this is what cultural studies does: it interprets culture. As such, cultural studies has two albeit inter-linked areas of inquiry: the field of culture itself and the field of methodologies for interpreting that culture. Cultural studies has, to put it simply, an object of study. As such cultural studies does not differ, at least not structurally, from other more traditional and established disciplines. Its field may be larger - more complex - and its theoretical resources more fluid, but there seems nevertheless to be an assumption of a determinate relation between the two: find your object, your cultural phenomenon, and then read it. Cultural studies in this sense operates as a kind of colonisation. It panders to our desire to understand the world and to make sense of our experiences in that world. In this sense cultural studies partakes in what Lyotard once called the "fantasies of realism" (Lyotard 1984: 74).'

In the above, cultural studies can be thought of as part of the strata of the academia. Here cultural studies works as a mechanism to organise - and thus define - 'culture', and in doing so organise the subject. In this sense, and in common with other disciplines, cultural studies operates to fix knowledges. This is particularly the case with the kind of cultural studies which develops out of Marxian - and Frankfurt School - theory. That is, a cultural studies whose project is representational (represents culture from a theoretical perspective). Or, conversely cultural studies as critique of representation (cultural studies as 'ideological critique'). It was of course Adorno who identified this first project as the work of the culture industry: the latter's tendrils reaching further and further into everyday life. And yet cultural studies can itself be understood as an industry (a peculiarly academic industry), mirroring the work of capitalism in its desire to interpret reality. The second project - ideological critique - is characteristic not just of the Frankfurt School but also of the deconstructionists and their associated allies (the 'signifier enthusiasts'). Here the work of cultural studies (understood as Critical Theory), involves an attempt at understanding the movement of capitalism (the workings of ideology - understood as representation), as well as an intent on locating resistances (hence the importance for Adorno, and others, of the work of art). But these resistances are, as deconstruction shows us, difficult to

Lyotard 'defines' these fantasies as operating: "whenever the objective is to stabilise the referent, to arrange it according to a point of view which endows it with a recognizable meaning, to reproduce the syntax and vocabulary which enable the addressee to decipher images and sequences quickly, and so to arrive easily at the consciousness of his own identity as well as the approval which he thereby receives from others - since such structures of images and sequences constitute a communication code among them all. This is the way the effects of reality, or if one prefers, the fantasies of realism, multiply" (ibid). Hence, for Lyotard the importance of the artist and writer who counteract this 'reality effect'; who are precisely "working without rules in order to formulate the rules of what will have been done" (ibid: 81). In this essay I want to suggest that cultural studies might take on the role which Lyotard assigns to art. 
articulate (they seem to be always already articulated within the dominant), hence, for Adorno at least, such sites are inevitably figured as utopian. ${ }^{2}$

Lyotard once remarked that the problem of this negative critique is that the thing critiqued (indeed, the act of critique itself) often, inevitably, ensnares the critic. The critique becomes defined, determined by, the object of criticism. ${ }^{3}$ The 'sites of resistance' are, if you like, predetermined by that which they resist; no rules (the 'rules of representation') are broken. Cultural studies becomes in this sense complicit with the dominant reality; it works within certain spatial and temporal parameters. As Bataille might say it operates within 'mundane time' and on the human register. ${ }^{4}$ Indeed it assumes - and reinforces - a certain notion of a subject (however fragmented) and a certain notion of an object (however expanded).

Could there be another way of understanding the work of cultural studies? One which replaces this fundamentally hermeneutic project with a heuristic one? Cultural studies as an 'experimental milieu', as a project in which pragmatics, getting things done, replaces understanding. Cultural studies as an affirmative and strategic mapping of the possibilities of life. Indeed cultural studies as a kind of 'war machine' precisely against interpretation - and against representation.

In fact to a certain extent cultural studies has always had this parallel project. At the same time as demarcating territories it produces lines of flight, deterritorialisations into other milieux. Lines of flight which themselves become territorialised and subsequently new lines of flight. Cultural studies has, as all disciplines have, as well as its cops and its priests, its mavericks, its adventurers,

2 "Art's utopia, the counter-factual yet-to-come is draped in Black, it goes on being a recollection of the possible with a critical edge against the real, as promised by its impossibility. Art is the promise of happiness, a promise that is constantly being broken" (Adorno 1984). As we shall see, Gilles Deleuze turns away from this emphasis on the possible versus the real, replacing them instead with the categories of the virtual and the actual. Such a reconfiguration involves a rethinking of the effectiveness of art (and of the aesthetic), understood as no longer a promise of 'another world', but rather as an access point into other worlds.

${ }^{3}$ Lyotard writes that the danger with negative critique is that "the thing criticised holds back and even consumes the one who criticises, as Sodom petrified Lot's wife" (1988a: 155).

${ }^{4}$ See for example Bataille's essay on Prehistoric Painting: Lascaux or the Birth of Art (1980). Here Bataille contrasts 'work time' (to do with utility; with being human) with 'sacred time', precisely a transgression of this norm (a move 'into' the natural - cosmic realm). Bataille argues that the practice of cave painting (understood as ritual) involved a 'playful' activity aimed specifically at accessing another mode of being and a different temporal order - characterised as the 'marvelous': "We must finally admit that, in every ritual operation, the seeking after a specific end is never but one amongst a number of its operators' motives: these motives derive from the whole of reality, its religious and sensible (aesthetic) sides alike. In every case they imply what has always been art's purpose: to create a sensible reality whereby the ordinary world is modified in response to the desire for the extraordinary, for the marvellous" (ibid: 34 ). 
its sorcerers. These figures are to be found in the margins, at the edge, in the no man's land between disciplines. For them cultural studies - intellectual work in general - is a project embarked on without preset rules and without predetermined objects. It is a 'voyage of discovery', a journey which itself produces the terrain it maps. Two such adventurers - we might call them philosophers (philosophy understood here as active concept creation) - are Gilles Deleuze and Felix Guattari.

Their project, at least as it appears in their second volume of Capitalism and Schizophrenia, A Thousand Plateaus, is not to understand the world (to understand culture) but rather to create the world differently; to overcome the "ontological iron curtain between being and things" rather then to reinforce it (Guattari 1995a: 8). Such a project involves less an object of study - indeed objects might themselves strategically disappear in such a project. Even less does it involve a reading, an interpretation of objects (that is, it has no clearly defined, fixed, subject either). Instead it involves a pragmatics, the creation of 'psychic tools' with which to reorder our 'selves' and our world. I want now to briefly map out how one of these concept-tools - the rhizome - operates, and how a 'rhizomatics' might help in reconfiguring the cultural studies project. In doing so I will also map the rhizome's 'rhizomatic' connections with other Deleuzian concepts and with other allies:

1 and 2. Principles of connection and heterogeneity: any point of a rhizome can be connected to anything and must be... A rhizome ceaselessly establishes connections between semiotic chains, organisations of power, and circumstances relevant to the arts, sciences, and social struggles. (Deleuze and Guattari 1988: 7)

The rhizome is anti-hierarchical and a-centred. No single organising principle predetermines the consistencies and compatibilities between the network of its elements. The rhizome precisely fosters transversal, even alogical, connections between heterogeneous events. No longer a field of culture distinct from nature, indeed, no longer a realm of theory distinct from its object; and no longer the work of politics separated from the practice of art. Instead we have a continuous open system, with multiple entrance ways, of contact and communication between different milieux. Cultural studies could be understood as precisely this programme of geometry. Here cultural studies becomes a map - a strategy for reconfiguring our experiences. Thinking cultural studies as rhizome involves an affirmation of the former's interdisciplinary, or even transdisciplinary function; it removes blockages and opens us up to other adventures, other voyages. Cultural studies, in this place, is very much a pragmatic programme. An escape root/route from fixity and stasis. A means with which to enter smooth space. ${ }^{5}$

\footnotetext{
5 "Smooth space is filled by events or haecceities, far more than by formed and perceived things. It is a space of affects, more than one of properties" (Deleuze and Guattari 1988: 479).
} 
And this implies not just a reorientation in the object but a reconfiguration of the subject as well. The rhizome is out there but also in here (indeed, the rhizome renders 'inner' and 'outer' - as ontological categories - redundant). Guattari calls this project resingularisation, and for him it is predominantly a material, pragmatic project. Here he is writing about his work with psychotics at La Borde clinic in France. The extract is taken from his book Chaosmosis in which Guattari outlines what he sees as a new ethico-aesthetic paradigm for thinking subjectivity:

...certain psychotic patients, coming from poor agricultural backgrounds, will be invited to take up plastic arts, drama, video, music, etc., whereas until then, these universes had been unknown to them. On the other hand, bureaucrats and intellectuals will find themselves attracted to material work, in the kitchen, garden, pottery, horse riding club. The important thing here is not only the confrontation with a new material of expression, but the constitution of complexes of subjectivation: multiple exchanges between individual-group-machine. These complexes actually offer people diverse possibilities for recomposing their existential corporeality, to get out of their repetitive impasses and, in a certain way, to resingularise themselves. Grafts of transference operate in this way, not issuing from ready-made dimensions of subjectivity crystallised into structural complexes, but from a creation which itself indicates a kind of aesthetic paradigm. One creates new modalities of subjectivity in the same way an artist creates new forms from a palette. (Guattari 1995: 6-7)

The possibility of making transversal connections between people and between people and things is, for Guattari, not so much a cure for psychosis, even less a reintegration of the psychotic into society (the re-oedipalisation enacted by psychoanalysis), rather it is a means by which individuals can reorganise, or resingularise themselves in a creative and affirmative manner. For Guattari, La Borde is a machinic assemblage - a space in which different complexes can aggregate together. Importantly, and like the rhizome, this assemblage is always opening up to an outside. The machine, the machinic assemblage, is not to be confused with, or reduced to the merely technical machine. Indeed the machinic assemblage can best be understood as a function, a fluid function of connectivity and deterritorialisation. In this sense the rituals of archaic societies (complexes of signifying and a-signifying functions) are as much machines as the city megamachine. The rhizome too is in this sense machinic. Or the machine is rhizomatic. Both foster connections, both deterritorialise. And at stake in both is an 'overcoming' of the subject / object split. As Guattari writes elsewhere:

The autopoietic and 'hypertextual' position of the machine thus possesses a pragmatic potential, which allows for a creative standpoint of machinic composition, occurring in the face of the ontological iron curtain which separates the subject on one side from things on the other. (Guattari 1995a: 12) 
This is a kind of return to the project of cultural studies as outlined in my beginning; cultural studies as a strategy for ending alienation. But here this 'healing' (this reconciliation) of the split between subject and object is not utopian, not transcendent, but is instead reconfigured as immanent. An immanent aesthetics. A pragmatic programme of de- and re-subjectification.

Back to Deleuze and Guattari and to the rhizome:

3. Principle of multiplicity: it is only one when the multiple is effectively created as a substantive, 'multiplicity', that it ceases to have any relation to the One as subject or object, natural or spiritual reality, image and world... A multiplicity has neither subject nor object, only determinations, magnitudes, and dimensions. (Deleuze and Guattari 1988: 8)

Thinking cultural studies as multiplicity involves a re-mapping of the terrain of cultural studies; subject and object disappear replaced by 'determinations, magnitudes and dimensions', moments of intensity and lines of flight. Indeed, thinking cultural studies as rhizome implies a different kind of strategic individuation; not a different kind of reading but a transformation:

What we're interested in, you see, are modes of individuation beyond those of things, persons or subjects: the individuation, say, of a time of day, of a region, a climate, a river or a wind, of an event. And maybe it's a mistake to believe in the existence of things, persons, or subjects. (Deleuze 1995: 26)

In this place, cultural studies creates the world differently. Like a kind of Science Fiction, we enter a world populated not by people and things but by events, haecceities, and intense thresholds. The human - as organised, signified, subjectified - disappears. Or at least becomes little more than a strategic position (a territory), a launch pad into other worlds.

How to think this multiplicity of which we are part without reducing it to the simple? How to think an-original complexity that does not arise - or return to - the One? For Deleuze and Guattari this must involve a subtraction: always, subtract the leader, the general. Always subtract the centre. Always $n-1$. Michel Serres, another ally in our rhizomatic project, attempts a similar task - thinking the multiple - in his book Genesis. Serres is particularly wary of the hegemony of the concept - that mechanism of classification which distributes and produces unities. For Serres, instead, a kind of quasi-concept is needed to think the work of the multiple:

Time-as-weather, fire-as-heat are not concepts in the usual sense. Clock-time is such a concept, entropic time is, perhaps, another such, and temperature as well. A cloud is an aggregate, a nebulous set, a multiplicity whose exact definition escapes us, and whose local movements are beyond observation. A flame is an aggregate... that is even more nebulous. Heat and flame, cloud and wind, climate and turbulences, we could refer to them as concepts of multiplicities. (Serres 1995: 103) 
Like Deleuze and Guattari, Serres attempts to individuate the world differently. To 'free' the multiplicity from the shelter of the unifying concept. For Serres the world is made up not from 'well formed' objects but by aggregates which require a different kind of thought altogether. Indeed, for Lyotard, yet another ally, thoughts are themselves cloud-like:

Thoughts are not the fruits of the earth. They are not registered by areas, except out of human commodity. Thoughts are clouds. The periphery of thoughts is as immeasurable as the fractal lines of Benoit Mandelbrot. Thoughts are pushed and pulled at variable speeds. They are deep, although core and skin are of the same grain. Thoughts never stop changing their location one with the other. When you feel like you have penetrated far into their intimacy in analysing their so-called structure or genealogy or even post structure, it is actually too late or too soon. (Lyotard 1988b: 5)

Such a rethinking of thought involves a rethinking of the cogito; the 'mind' is no longer the origin of thought, but is a kind of threshold, or temporary turbulence, within a thought cloud-field. Here thought, thinking, is itself a multiplicity; creative thinking as such involves a reconnection with this nebulous realm (of potentialities) beyond (in fact, always parallel) to the subject.

Deleuze and Guattari likewise, at times, turn away from the concept and rethink thought. Hence the importance of science, involving function (we might say, involving a 'machinic mapping' of the world), and of art, involving affects. When concepts are considered (in the philosophical project per se) they are understood creatively; active concept creation as a means of problem solving, precisely to 'get something done'. For example Deleuze's concept of difference mapped out before his collaboration with Guattari. Here the world is no longer thought as being comprised of distinct entities - not even of aggregates of smaller and smaller parts. Instead a notion of difference becomes the condition of possibility for phenomena. But this difference is not that between already demarcated signifiers (it is not a semiotic) rather it is a difference of intensity (we might say a difference of affect):

Every phenomenon refers to an inequality by which it is conditioned. Every diversity and every change refers to a difference which is its sufficient reason.

\footnotetext{
${ }^{6}$ See Deleuze and Guattari's What is Philosophy? (Deleuze and Guattari 1994). Brian Massumi has written an interesting, and instructive, essay on affect in relation to the human brain/body configuration (Massumi 1996). He demonstrates that affects understood as a-signifying 'events' passing across the body - everywhere and always accompany (and in some senses determine) the more obvious (i.e. signifying and structuring) elements of subjectivity. In fact we might say, with Massumi, that the universe of affect (the universe of the virtual) often works to interfere with linguistic expression, and indeed the other 'subject constructing' mechanisms of late capitalism. Massumi, via Spinoza, gives this project of thinking affect a name: ethics (ibid: 222).
} 
Everything which happens and everything which appears is correlated with orders of differences: differences of level, temperature, pressure, tension, potential, differences of intensity. (Deleuze 1994: 222)

Such a reconceptualisation allows us to move from a signifying register to an asignifying (an affective) one. The world - as multiplicity - is constituted by moments of, and differences in, intensity. Of course, to a certain extent this is not new. Indeed it may involve a return to a pre-theological, a pagan, mapping of the world. Deleuze has himself positioned his work in a genealogy of 'bastard' - or pagan - philosophers from Heraclitus to Nietzsche. A line of nomadic thought everywhere accompanying state philosophy as its mutant twin. Or of course we could turn away from the west to the east - and to the immanent philosophies/religions. Hinduism can be characterised as a multiplicity - a bewildering and muddling collection of deities with no apparent order or centre. Hence the apparent difficulty for the Western mind in grasping this system which is not a system. But in our reading of Hinduism this multiplicity is also reducible to the One. The different Gods are understood as fragments, specific incarnations, of the One. So much for the Western interpretation of this magical multiplicity. An interpretation which brings Hinduism closer to Christianity. In fact, with Deleuze we have something even further removed from such pantheist mythologies: the world as conditioned reality. In this world (our world seen differently) there are only conditions which produce other conditions. Here process (movement) replaces stasis (fixity) as the world's - and the subject's modus operandi. We are closer to the Buddhist - or the Taoist here. No essences, indeed no theology (no 'representation'), but a 'fundamental' insubstantiality, impermanence, and interpenetration of all phenomena. The world as a vortex of energy; the world, and ourselves within that world, as a "region of fire" (Lyotard 1993: 13).

"Multiplicities are defined by the outside: by the abstract line, the line of flight or deterritorialisation according to which they change in nature and connect with other multiplicities" (Deleuze and Guattari 1988: 9). Cultural studies, as multiplicity is fluid. What it 'is' is defined by its outermost edge - its line of flight. As such cultural studies is a dynamic, open system. One that changes its nature as the number of its dimensions increase (as it crosses into other plateaus). Cultural studies as such does not name a discipline but rather a function. Cultural studies is a deterritorialisation from other disciplines, from academia, and inevitably from itself. For as soon as cultural studies becomes fixed (becomes a discipline) then the real work of cultural studies will be going on elsewhere.

4. Principle of asignifying rupture: against the oversignifying breaks separating structures or cutting across a single structure. A rhizome may be broken, shattered at a given spot, but it will start up again on one of its old lines, or on new lines... Every rhizome contains lines of segmentarity according to which it is stratified, territorialised, signified, attributed, etc., as well as lines of deterritorialisation down which it constantly flees. (Deleuze and Guattari 1988: 9) 
Not the rhizome versus the root (no dualities); indeed it is the nature of the rhizome to be broken, it is the nature of the root to produce rhizomes. For in reality these two are entwined; the rhizome in the root and the root in the rhizome. Cultural studies, within the academia, may be ossified, may be frozen, but this does not mean we have to go elsewhere. Rather we switch registers: "A new rhizome may form in the heart of a tree, the hollow of a root, the crook of a branch. Or else it is a microscopic element of the root tree, a radicle, that gets rhizome production going" (ibid: 15).

Strategically this might mean that as well as looking to other milieux (Eastern philosophy, the new sciences, techno-culture, etc), and at minor literature (that which has been left outside the canon of cultural studies), we might also look to the redundancies within cultural studies: lines of flight from traditional representational paradigms - in fact suggested by those paradigms. And here we return to those issues I raised at the beginning. Cultural Studies as strata - but strata which contain within possibilities of destratification. For you do not get the one without the other. Cultural studies as a constant process, a constant movement, and also cultural studies as the interruption (the freezing) of this movement. Cultural studies as rhizome (always between disciplines), and then, rhizomes in cultural studies. In fact cultural studies inevitably produces the stratification of lines of flight (reinstalls the signifier) and yet, in so doing, prepares the ground, the territory, for future deterritorialisations.

Cultural studies here is a smooth and a striated space. A space of expansion, of experimentation, and also a space that is organised and classified; one does not come about without the other. Every nomad always has several base camps, temporary consolidations of territory depending on the seasons territorialisations which produce deterritorialisations. Indeed cultural studies is not, and cannot be, a wild destratification. Such a line of flight is ultimately destructive. As Deleuze and Guattari say in another of their plateaus: "Staying stratified - organised, signified, subjected - is not the worse that can happen: the worse that can happen is if you throw the strata into demented or suicidal collapse, which brings them back down on us heavier than ever" (ibid: 161). Indeed:

you have to keep enough of the organism for it to reform each dawn; and you have to keep small supplies of signifiance and subjectification, if only to turn them against their own systems when the circumstances demand it, when things, persons, even situations, force you to: and you have to keep small rations of subjectivity in sufficient quantities to enable you to respond to the dominant reality. (Ibid: 160)

The watch word in this project of deterritorialisation - this project of cultural studies - is caution. Always proceed with the smallest of doses. And always proceed from a consolidated territory. 
This is how it should be done: lodge yourself on a stratum, experiment with the opportunities it offers, find an advantageous point on it, find potential movements of deterritorialisation, possible lines of flight, experience them, produce flow conjunctions here and there, try out continuums of intensity segment by segment, have a small plot of new land at all times. It is through a meticulous relation with the strata that one succeeds in freeing lines of flight. (Ibid: 161)

This is not a programme of escapism. Even less the outline of a utopian metaphysics. Rather it is a call to arms and a call for attention to be focused on the actual, if only to unlock the potential becomings, the virtualities encapsulated within every moment. And this virtual is not some 'Other' place (not even an endlessly deferred one): "Indeed, the virtual must be defined as strictly a part of the real object - as though the object had one part of itself in the virtual into which it plunged as though into an objective dimension" (Deleuze 1994: 208209). The virtual is another (temporal) dimension of the object - or rather, and following Bergson, the virtual is the 'completely determined structure' of the object, and the actual is but a 'part'. We only ever encounter this actual part ('reality'); the project of cultural studies might be to access the other (virtual) potentialities; in fact to actualise the virtual. And this is where the interdisciplinary nature of cultural studies once more becomes important. The inter is now between the actual and the virtual, for, as Brian Massumi asserts, it is "at the edge of the virtual, where it leaks into actual, that counts. For the seeping edge is where potential, actually is found" (1996: 236).

For Deleuze this actualisation of the virtual is a "genuine creation" (Deleuze 1994: 213). As such it is important that the virtual be differentiated from its 'near enemy': the possible (the utopian).

The only danger in all this is that the virtual could be confused with the possible. The possible is opposed to the real; the process undergone by the possible is therefore 'realisation'. By contrast, the virtual is not opposed to the real; it possesses a full reality by itself. The process it undergoes is actualisation. It would be wrong to see only a verbal dispute here: it is a question of existence itself. (Ibid: 211)

Indeed, I would argue that the dominant model of cultural studies within the academy is precisely one based on the possible. Either the melancholy science (as Gillian Rose called it) of Adorno's utopian blinks or the equally melancholic, even pessimistic, endless deferral of the possible heralded by Derrida and de Man. Cultural studies which replaces the possible with the virtual becomes a much more affirmative project. Affirming the fullness of life (understood as endless creativity) rather than lamenting its lack.

In fact this project can take place from within the heart of the other. It is not as if a rhizomatic cultural studies looks elsewhere - it is based in the same terrain, albeit it thinks that terrain differently. For example cultural studies might still be involved in a kind of semiotic project - but it might think the sign 
differently (as signifying (ideological, psychoanalytical, etc.) but also as having asignifying functions), something Lyotard seems to hint at:

First therefore, a different reaction, a different reception. We do not suppose, to begin with, that the signs... transport messages which are communicable in principle. We don't start off by saying to ourselves: someone or something is speaking to us here, so I must try to understand. To understand, to be intelligent, is not our overriding passion. We strive instead to be set in motion. Consequently our passion would sooner be the dance, as Nietzsche wanted, and as Cage and Cunningham want. (Lyotard 1993: 50)

Here the sign becomes an intensity, a trigger point for movement (a 'setting in motion'). Indeed the tensor can be understood as precisely the affective side of the sign. If interpretation still has a role it is in this sense: to reactivate the frozen event; to unravel the virtual pasts and virtual future (the potentialities) of the sign - the latter understood as 'meaningful' but also as productive. Interpretation is our confrontation with this bundle of energy, this haecceity; precisely a meeting, an encounter, between force fields.

5 and 6. Principle of cartography and decalcomania: a rhizome is not amenable to any structural or generative model. It is a stranger to any idea of genetic axis or deep structure...The rhizome is altogether different, a map and not a tracing... What distinguishes the map from the tracing is that it is entirely orientated towards an experimentation in contact with the real... The map is open and connectable in all of its dimensions; it is detachable, reversible, susceptible to constant modification. It can be torn, reversed, adapted to any kind of mounting, reworked by an individual, group, or social formation. It can be drawn on a wall, conceived of as a work of art, constructed as political action or meditation. (Deleuze and Guattari 1988: 12)

So, nothing precedes the making of the rhizome. The rhizome is not a representation. It does not trace, or photograph, something that came before. And this is not to put in operation an opposition. As Deleuze and Guattari say, maps can be traced and tracings can become maps. "It is a question of method: the tracing should always be put back on the map" (ibid: 13). Cultural studies here becomes programmatic and diagrammatic: "The diagrammatic or abstract machine does not function to represent, even something real, but rather constructs a real that is yet to come, a new type of reality" (ibid: 142).

Again this 'new type of reality' is not utopian, nor transcendent but immanent to this reality. Cultural studies in this sense is indeed an 'abstract machine'; a function of deterritorialisation operating from within already existing strata. In their conclusion to A Thousand Plateaus Deleuze and Guattari again outline the functioning of the 'abstract machine'. Their definition might equally apply to a 'rhizomatic' cultural studies:

Abstract machines operate within concrete assemblages: They are defined by ... the cutting edges of decoding and deterritorialisation They draw these cutting edges. 
Therefore they make the territorial assemblage open onto something else, assemblages of another type, the molecular, the cosmic; they constitute becomings. Thus they are always singular and immanent.

And so what are the implications of all this for cultural studies - as it is practised today - and for 'interdisciplinarity'? Well, as regards the latter cultural studies is 'interdisciplinary' in the sense that it is between disciplines, it is what 'produces' these 'disciplines' - these bodies of knowledges - deterritorialisations. We might, in this sense - and to borrow a notion from Alain Badiou - understand cultural studies as an event site, "a point of exile where it is possible that something finally might happen" (Badiou 2000: 84-85). Less certain is what this project - of cultural studies - might look like; how to write this, how to teach it? Again, as regards the latter, cultural studies is a pragmatics. Students must be given the tools with which to create their own concepts (their own quasi concepts) and produce their own deterritorialisations. And it is at this point that the nature of pedagogy changes. No longer, or not only, imparting a body of knowledge, teaching a set of competences, but an encouragement to experiment, an encouragement to incompetence. No longer producing specialists but providing 'tool boxes'.

And the practice, or the 'writing', of cultural studies itself is no longer an interpretation but becomes an experiment, an 'exploratory probe', an event amongst events. In such a project other media might equally be utilised (no more hegemony of the essay/article). Indeed cultural studies, in common with other creative practices, might involve taking up different materials from different milieux. At stake in these experiments is the accessing of other worlds. Not worlds 'beyond' this one (no transcendent, nor utopian principle) but worlds, 'incorporeal universes' as Guattari calls them, virtual and immanent in this one. Cultural studies might be a name for this work of imagination.

And in such a project our allies might not necessarily be within the Academy. Our allies will in fact be on the outside, or at least at the outermost edge. Indeed cultural studies is also about locating these allies, these anomalies that stalk the fringes. For these figures - these 'events' - these moments of intensity - are the border guides/guards, the access nodes into other worlds. A certain notion of politics might - strategically - disappear here (the 'subject' of politics himself disappears), indeed this project might be best characterised as ethical. In as much as it involves exploring the potential for becoming - the potential for self-overcoming. But this is not necessarily to disavow the political project, the work of representation and of representational critique. Rather it is to reconfigure these projects as 'molar', which, important though they might be, when focused on exclusively, efface the 'molecular' (understood as the realm of affect) of which they are constituted. As such the molecular - the rhizome - is a kind of guerrilla war against representation. A war with no winner and in which the taking of sides is always strategic and pragmatic. Cultural studies is the name of this project and the site within which this project takes place. Cultural studies as rhizome but also and always the burgeoning rhizomes within cultural studies. 


\section{Bibliography:}

Adorno, Theodor (1984) Aesthetic Theory, London: Routledge.

Badiou, Alain (2000) Deleuze: The Clamor of Being, trans. Louise Burchill, Minnesota: University of Minnesota Press.

Bataille, Georges (1980) Prehistoric Painting: Lascaux or the Birth of Art, London: Macmillan.

Deleuze, Gilles (1994) Difference and Repetition, trans. Paul Patton, London: Athlone Press.

Deleuze, Gilles (1995) Negotiations, trans. Martin Joughin, New York: Columbia University Press.

Deleuze, Gilles and Felix Guattari (1988) A Thousand Plateaus, trans. Brian Massumi, London: Athlone Press.

Deleuze, Gilles and Felix Guattari (1994) What is Philosophy? Trans. Graham Burchell and Hugh Tomlinson, London: Verso.

Guattari, Felix (1995) Chaosmosis: An Ethico-Aesthetic Paradigm, trans. Paul Bains and Julian Pefanis, Sydney: Power Publications.

Guattari, Felix (1995a) "On Machines", in Complexity: Architecture/ Art/Philosophy, trans. Vivian Constantinopoulos, London: Academy Editions.

Lyotard, Jean-François (1984) "Appendix: Answering the Question: What is Postmodernism?" in The Postmodern Condition, trans. Geoff Bennington and Brian Massumi, Manchester: Manchester University Press.

Lyotard, Jean-François (1988a) "Beyond Representation", in The Lyotard Reader, ed. Andrew Benjamin, Oxford: Basil Blackwell.

Lyotard, Jean-François (1988b) Peregrinations: Law, Form, Event, New York: Columbia University Press.

Lyotard, Jean-François (1993) Libidinal Economy, trans. Iain Hamilton Grant, London: Athlone Press.

Massumi, Brian (1996) "The Autonomy of Affect", in Deleuze: A Critical Reader, ed. Paul Patton, Oxford: Blackwell.

Serres, Michel (1995) Genesis, trans. Genevieve James and James Nielson, Ann Arbor: University of Michigan Press. 